\title{
Establishment of highly invasive pancreatic cancer cell lines and the expression of IL-32
}

\author{
KOHJI TAKAGI, JOHJI IMURA, AKIKO SHIMOMURA, AKIRA NOGUCHI, TAKASHI MINAMISAKA, \\ SHINICHI TANAKA, TAKESHI NISHIDA, HIDEKI HATTA and TAKAHIKO NAKAJIMA \\ Department of Diagnostic Pathology, Faculty of Medicine, Academic Assembly, \\ University of Toyama, Toyama, Toyama 930-0194, Japan
}

Received December 15, 2019; Accepted May 27, 2020

DOI: $10.3892 / \mathrm{ol} .2020 .11825$

\begin{abstract}
Compared to tumors of other organs, pancreatic cancer is highly aggressive; with one of its biological features being that, despite a prominent fibrotic stroma, there is remarkable infiltration of tumor cells. This characteristic is considered to be the main reason for the poor prognosis of patients with pancreatic cancer. Therefore, in order to elucidate the factors that contribute to this high invasiveness, a selective invasion method was used to establish four highly invasive subclones from six human pancreatic cancer cell lines. The results demonstrated that two cell lines did not exhibit enhanced invasiveness. Microarray analysis revealed that, in the highly invasive cell lines, several genes were expressed at high levels, compared with the original cell lines. These highly expressed genes were recognized only in highly invasive cells. Among them, $I L-32$ was most strongly upregulated in the highly invasive cells, compared with cells with a low invasive potential, as well as the original cells. RT-qPCR and western blot analysis confirmed the high levels of expression of IL-32 in highly invasive cells at the RNA and protein levels. In addition, immunohistochemical analysis of resected surgical materials revealed that the tumor cells expressed IL-32 and, in particular, many IL-32 positive cells were seen at the invasive front of the tumor tissue. IL-32 is a cytokine that is widely involved in the development of cancer and has recently received considerable attention. This cytokine has multiple splice variants and shows a wide variety of behaviors, depending on the tumor type and primary organ. Although some hypotheses have been proposed to explain the activity of IL-32, a unified view has not been agreed. In the present study, through the establishment of highly invasive cells from pancreatic cancer and a comprehensive gene analysis,
\end{abstract}

Correspondence to: Dr Johji Imura, Department of Diagnostic Pathology, Faculty of Medicine, Academic Assembly, University of Toyama, 2630 Sugitani, Toyama, Toyama 930-0194, Japan

E-mail: imura@med.u-toyama.ac.jp

Key words: pancreatic cancer cell, invasion, comprehensive genomic analysis, cell culture, interleukin-32 it is suggested that IL-32 may serve an important role as a molecule involved in the invasiveness of this neoplasm.

\section{Introduction}

Pancreatic cancer is a leading fatal neoplasm and the even at the early stage, invasion of the surrounding organs and metastases often are already present $(1,2)$. The biological properties of pancreatic cancer are characteristic; it is richer in fibrous stroma in the tumor tissue than other carcinomas (3), but nevertheless this 'desmoplastic change' is prominent, the tumor cells are able to invade the hard interstitium easily.

Various cellular signals are involved in the regulation of invasion by pancreatic cancer cells. For example, the epithelial mesenchymal transition (EMT) and the interaction between the cancer cells and stroma are important. It has been suggested that bone morphogenetic protein (BMP), a member of the transforming growth factor- $\beta$ (TGF- $\beta$ ) family, and various cytokines contribute to these mechanisms $(4,5)$. On the other hand, in order to acquire invasiveness, the cancer cells must be motile and able to break down the surrounding hard stroma. The control of motility is a feature of TGF- $\beta$ and degradation of the stroma involves various matrix metalloproteinases (MMPs). Many past reports about this invasive phenomenon have examined the relationship between the expression of individual factors and invasiveness. However, this approach requires time and effort to identify the factors involved. In order to solve these problems, it would be useful to first establish highly invasive cells and then to identify the molecules that are highly expressed in these cells, as a means of analyzing comprehensively the factors that regulate invasiveness. Methods for establishing highly invasive cells include in vitro studies using an invasion assay (IA method) and in vivo studies using transplantation into nude mice (6). The latter combines the two phenomena of invasion and metastasis and the mechanism is complicated. In the IA method, it is considered that various molecules are secreted when the cells migrate into the gel and that factors regulating motility also must be involved. The IA method was adopted for this study because it seems to be a useful approach that, in several respects, is most suitable for establishing highly invasive cells.

The multistep carcinogenesis of pancreatic cancer is proposed as follows: a tumor (pancreatic intraepithe- 
lial neoplasm: PanIN) develops from normal tissue and progresses to PanIN-1 (hyperplasia), PanIN-2 (atypia) and PanIN-3 (carcinoma-in situ), as genetic mutations accumulate. Eventually, it becomes invasive pancreatic cancer (1). Previous studies have shown that KRAS, CDKN2A, TP53, and $S M A D 4$ are the four major genes mutated in pancreatic cancer cells, through the sequencing of a vast array of cancer-related genes in invasive pancreatic cancer. In addition, it has been suggested that twelve cell signaling pathways involving these genes are involved in the development of cancer (7). Genetic studies of pancreatic cancer have developed dramatically, and many significant biological and clinical interpretations have been made (8), but other genetic abnormalities remain to be described. In addition, there are many questions about how these signal transductions, directly or indirectly, define the characteristics of cancer cells and, in particular, control their invasiveness. From this point of view, finding a gene that controls invasiveness and determines the poor prognosis of pancreatic cancer will also contribute to, for example, the development of a molecular targeted therapeutic drug for future treatment.

Here, in order to search for factors that contribute to the invasiveness of pancreatic cancer, we attempted to establish multiple human pancreatic cancer cell lines with various capacities for infiltration. Furthermore, gene expression changes were analyzed comprehensively in these cells and genes that were specifically up-regulated in the cell lines that had acquired high invasiveness were examined.

\section{Materials and methods}

Cell lines and cell culture. The following six human pancreatic cancer-derived cell lines were used: PANC-1, AsPC-1, KP-3, BxPC-3, TCC-PAN2, and MIA PaCa-2. AsPC-1, $\mathrm{BxPC}-3$ and MIA PaCa-2 were obtained from the American Type Culture Collection (ATCC), PANC-1 and KP-3 from Kyusyu Cancer Center and TCC-PAN2 from the Japanese Collection of Research Bioresources Cell Bank. We originally recognized PANC-1 cells as other cells, but STR analysis showed that they were of the completely same origin as PANC-1 cells. Each cell line was maintained in RPMI-1640 culture medium (GIBCO Laboratories) with $10 \%(\mathrm{v} / \mathrm{v})$ fetal bovine serum (FBS) and $100 \mathrm{IU} / \mathrm{mL}$ penicillin and $100 \mu \mathrm{g} / \mathrm{mL}$ streptomycin. The cells were cultured at $37^{\circ} \mathrm{C}$ in $5 \% \mathrm{CO}_{2}$.

Establishment of highly invasive cell lines. Corning ${ }^{\circledR}$ BioCoatTM Matrigel ${ }^{\circledR}$ Invasion chambers (Corning) were used to establish highly invasive cell lines from the above pancreatic cancer cell lines. The chamber consists of two parts, with an $8 \mu \mathrm{m}$ hole at the bottom of the upper chamber (UC) and a thin polyethylene terephthalate membrane coated with matrix (the concentration is not disclosed by the manufacturer) on the surface. The cells were seeded at $2.5 \times 10^{4}$ in the UCs and incubated at $37^{\circ} \mathrm{C}, 5 \% \mathrm{CO}_{2}$ for 24 hours. Thereafter, only the cells that had migrated into the lower chamber (LC) were collected and cultured in a $100 \mathrm{~mm}$ diameter dish to increase their numbers. These cells were seeded in the UC again and the operation was repeated three times. The final cell line was designated as selected (S) and the original cell line was used as the parent $(\mathrm{P})$ in the following experiments.
Real-time monitoring of invasion ability. In order to evaluate the infiltration ability of the $\mathrm{P}$ and $\mathrm{S}$ cells, infiltration was measured in real time using the xCelligence system (ACEA Biosciences), following the manufacturer's instructions. Specifically, each cell line was maintained in serum-free RPMI 1640 medium for 4 hours before the measurement. The UCs of CIM-plates (Cell Invasion/Migration-Plate 16) were coated with Matrigel ${ }^{\circledR}$ Basement Membrane Matrix (Corning) diluted 20 times and allowed to stand at $37^{\circ} \mathrm{C}$ for 4 hours. The LC contained RPMI 1640 medium with 10\% FBS, which acted as a trigger for infiltration. For each cell type ( $\mathrm{P}$ and $\mathrm{S}), 2 \times 10^{4}$ cells were seeded in the UC and the resultant cell index was measured every 10 minutes for up to 48 hours, during incubation under $37^{\circ} \mathrm{C}, 5 \% \mathrm{CO}_{2}$ conditions.

RNA and protein isolation. Cells were harvested from sub-confluent monolayers and total cytoplasmic RNA was extracted using ISOGEN (Nippon Gene). The integrity of the RNA was evaluated using an Agilent 2100 Bioanalyzer (Agilent Technologies,). Concentrations were measured with a NanoDrop 1000 (Thermo Fisher Scientific, Inc.). Protein extraction was performed using similar subconfluent cells. After washing twice with phosphate buffered saline ( $\mathrm{pH} 7.4$ ), intracellular proteins were extracted using Complete Lysis-M (Roche) according to the manufacturer's instructions. The protein concentrations were calculated using a Coomassie Protein Assay kit and Thermo Multiskan FC (Thermo Fisher Scientific, Inc.) by measuring the absorbance at $595 \mathrm{~nm}$ with a known concentration of bovine serum protein as the standard.

Microarray analysis. In order to obtain biotin labeled cRNA, total RNA was amplified, labeled, and purified using a GeneChip ${ }^{\circledR}$ 3'IVT Express kit (Affymetrix; Thermo Fisher Scientific, Inc.) according to the manual. All samples were profiled on the GeneChip $^{\circledR}$ Human Genome U133 Plus v2.0 Array platform, array hybridization was performed using a Hybridization Oven 640 and washing was performed in a Fluidics Station 450. Slides were scanned using a GeneChip Scanner 3000 7G and Command Console Software 3.1 (Affymetrix; Thermo Fisher Scientific, Inc.) with default settings. The resulting data were analyzed using the MAS 5.0 algorithm of Gene Spring Software v12.5 (Agilent Technologies) and roughly extracted genes exhibiting a Fold Change (FC; $[\mathrm{S}]$ vs. $[\mathrm{P}])>2$. Volcano plot and heat map were also made by Transcriptome Analysis Console (TAC) v3.1 software (Affymetrix) adapting a default algorithm one-way between-subject ANOVA (unpaired) and a filter criteria ANOVA P-value $<0.05$.

Validation of reverse transcription-quantitative $P C R$ $(R T-q P C R)$. Quantitative PCR was used to evaluate the relative expression of the selected genes using cDNA from each cell line. First, we obtained cDNA using a Transcriptor Universal cDNA Master kit (Roche), according to the manufacturer's instructions. Next, quantitative PCR was conducted using a FastStart Essential DNA Green Master (Roche). According to the manufacturer's protocol, each cDNA and specific primer (Table I) were adjusted to final concentrations of $2.5 \mathrm{ng} / \mu \mathrm{L}$ and $500 \mathrm{nM}$, respectively, and then mixed in a total volume of $20 \mu \mathrm{L}$. We used a LightCycler ${ }^{\circledR} 480$ (Roche) for reaction by setting denaturation at $95^{\circ} \mathrm{C}$ for $10 \mathrm{sec}$, annealing at $60^{\circ} \mathrm{C}$ for $10 \mathrm{sec}$, and 
Table I. Primers used for reverse-transcription quantitative PCR.

\begin{tabular}{lll}
\hline Gene name & \multicolumn{1}{c}{ Forward sequence $\left(5^{\prime}-3^{\prime}\right)$} & \multicolumn{1}{c}{ Reverse sequence $\left(5^{\prime}-3^{\prime}\right)$} \\
\hline IL-32 & AGCTGGAGGACGACTTCAAA & AGAGCAGCAGAAACTCTGGA \\
PTX3 & CATCCAGTGAGACCAATGAG & GTAGCCGCCAGTTCAGCATT \\
ARHGDIB & AGTACGACGTGATCGTGCTG & AAATGGACAAAGATGATGAGAGTCTA \\
PCYT1B & TAGAGCACACATGCCCACAG & GACACTGGCAGTTGGTTTCA
\end{tabular}

IL-32, interleukin 32; PTX3, pentraxin 3; ARHGDIB, Rho GDP dissociation inhibitor beta; PCYT1B, phosphate cytidylyltransferase 1, choline, beta.
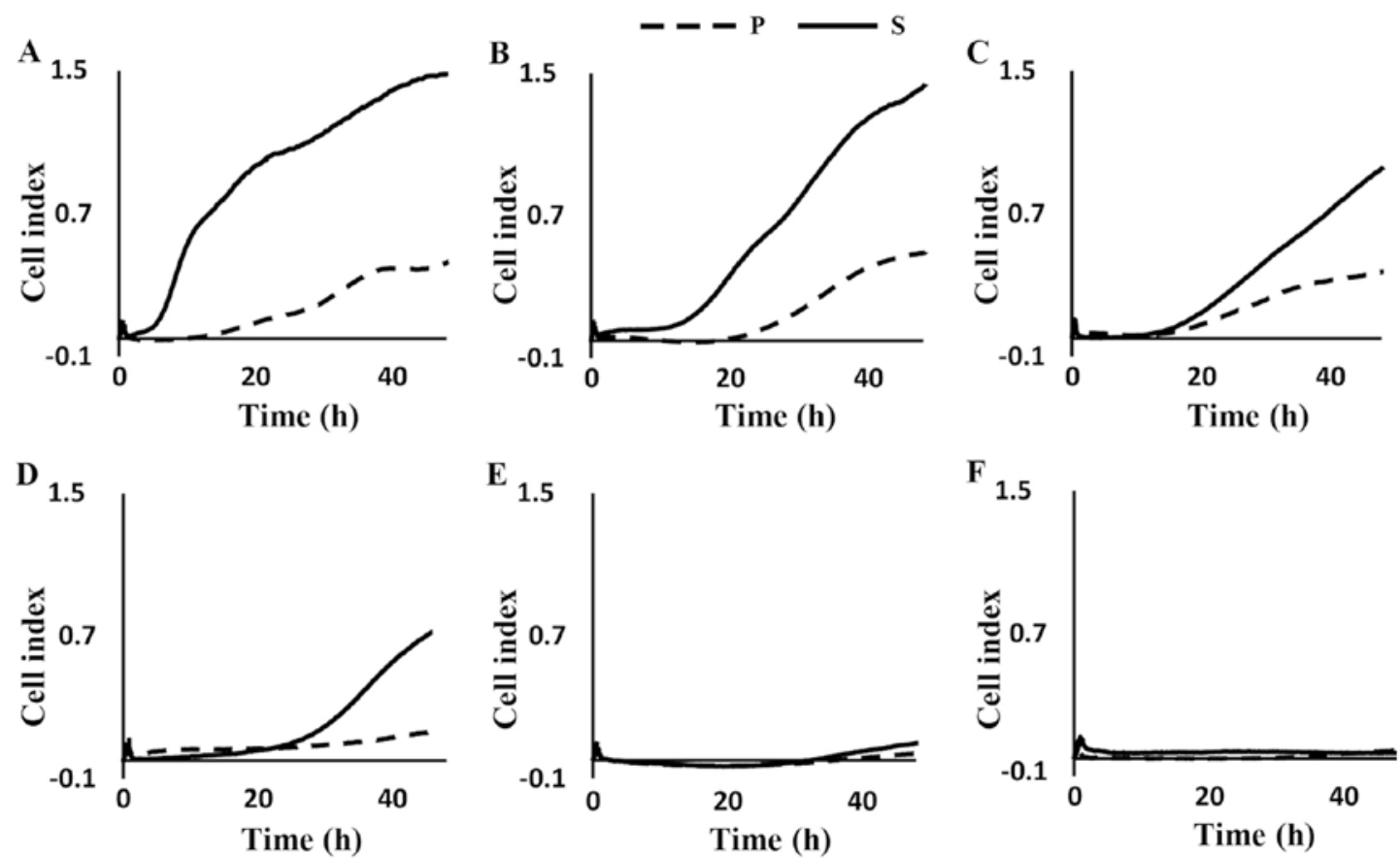

Figure 1. Establishment of highly invasive cell lines (A-D) and low invasive cell lines (E and F). Four cell lines (highly invasive group) had a greater invasion capacity in $\mathrm{S}$ than $\mathrm{P}$ but two cell lines (low invasive group) showed almost no change between P and S. (A) PANC-1, (B) KP3, (C) BxPC-3, (D) TCC-PAN2, (E) AsPC-1 and (F) MIA PaCa-2. S, selected; P, parent.

extension at $72^{\circ} \mathrm{C}$ for $15 \mathrm{sec}$ per cycle, with 45 cycles. Analysis was conducted using LightCycler Nano Software (Roche). The relative expression levels of mRNA were calculated relative to the those of $\beta$-actin, a housekeeping gene, based on quantitative cycles $(\mathrm{Cq})$ and using the relative $\mathrm{Cq}\left(2^{-\Delta \Delta \mathrm{Cq}}\right)$ method (9).

Western blot analysis. After adjusting the protein concentration, $10 \mu \mathrm{g}$ of each protein sample was separated by sodium dodecyl sulfate-polyacrylamide gel electrophoresis with 4-15\% gradient gels, followed by analysis using a Trans-Blot Turbo Transfer Pack (BioRad) and Trans-blot Turbo Blotting System (BioRad). For immunoblotting, the primary antibody reaction was performed by stirring with Can Get Signal Solution1 (Toyobo) at room temperature for 1 hour. The IL-32 antibody was a rabbit polyclonal anti-IL-32 antibody (dilution, 1:1000; cat. no. 11079-1-AP; Proteintech). The secondary antibody reaction was performed using a goat anti-rabbit IgG, horseradish peroxidase-linked antibody (dilution, 1:10000; cat. no. 7074S; CST Japan, Japan). Anti- $\beta$ actin antibody (dilution, 1:3000; cat. no. A5316; Sigma) was used as a loading control followed by the reaction with the corresponding horseradish peroxidase-linked secondary antibody (dilution, 1:10000; cat. no. 7076S; CST Japan). Detection and visualization were performed with an ImageQuant LAS500 (GE Healthcare) system using ECL Prime Western Blotting detection reagent (GE Healthcare) as the chemiluminescence detection reagent.

Immunocytochemical study. The S and P cultures of BxPC-3 cells were collected by centrifugation, and the cell pellets were fixed $15 \%$ citrated buffered formalin fixed and were paraffin embedded (FFPE). The thin sections were immunohistochemically reacted with IL-32 antibody (dilution, 1:100; cat. no. 11079-1-AP; Proteintech) and then the immunoperoxidase reactions were performed using a BenchMark GX automated IHC/ISH slide staining system (Roche), according to the manufacturer's protocols.

Statistical analysis. Statistical analysis was conducted using Student's t-test. $\mathrm{P}<0.05$ was considered to indicate a statistical significant difference and $\mathrm{P}<0.1$, significant tendency. 


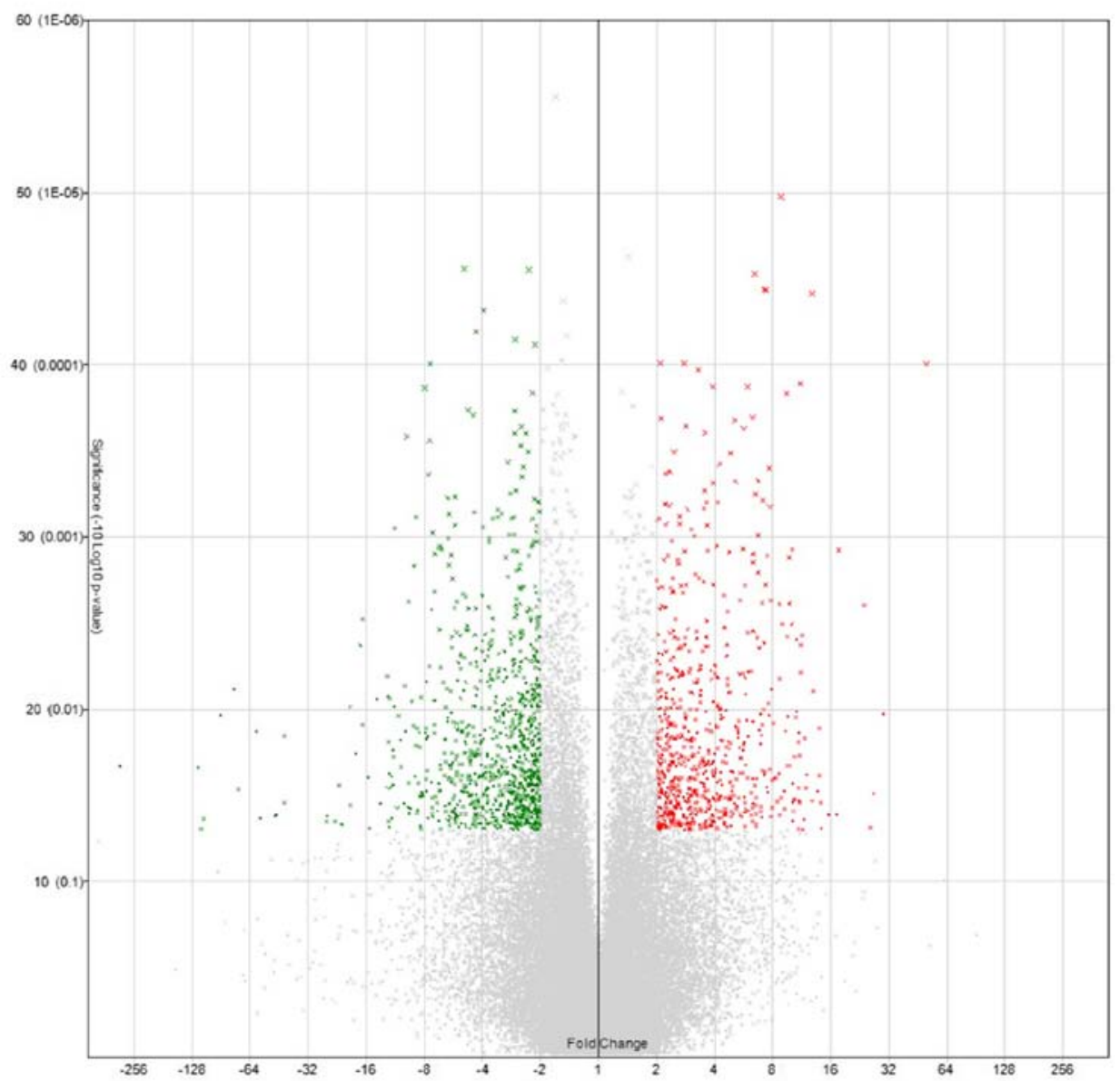

Figure 2. The volcano plot indicates the distribution of gene expression FC and p-values. Genes with $\mathrm{FC}>2$ and $\mathrm{P}<0.05$ (genes) are shown in red, and genes with FC $<-2$ and $\mathrm{P}<0.05$ (genes) are shown in green. Positive FC indicates upregulation compared with $\mathrm{P}$, while negative FC indicates down-regulation. FC, fold change; $\mathrm{S}$, selected; $\mathrm{P}$, parent

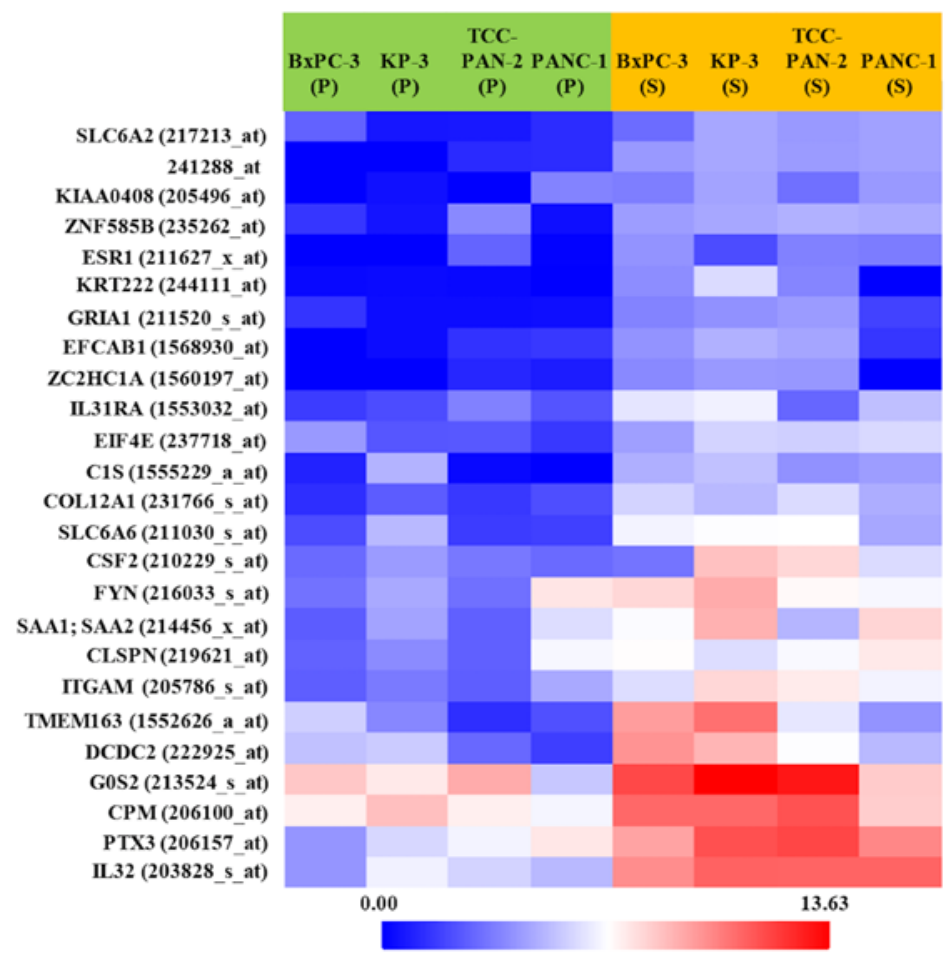

Figure 3. Heat map showing the top 25 differentially expressed genes with ANOVA $\mathrm{P}<0.05$ and $\mathrm{FC}>11$ between $\mathrm{S}$ and $\mathrm{P}$. Red indicates up-regulation and blue indicates down-regulation. The columns represent each highly invasive cell lines. On the rows, each gene symbol is described with a probe ID. FC, fold change; S, selected; P, parent. 
Table II. 20 genes arranged in descending order of FC in a comparison of S and $\mathrm{P}$ in the high invasive group.

\begin{tabular}{|c|c|c|c|c|c|}
\hline Probe set ID & $\mathrm{FC}(\mathrm{S}$ vs $\mathrm{P})$ & Gene symbol & Entretz Gene ID & Chromosomal location & UniGene ID \\
\hline 203828_s_at & 42.25 & IL32 & 9235 & chr16 p13.3 & Hs. 943 \\
\hline 229641_at & 27.23 & $C C B E 1$ & 147372 & chr18 q21.32 & Hs. 34333 \\
\hline 206157_at & 25.48 & РТХЗ & 5806 & $\operatorname{chr} 3$ q 25.32 & Hs. 591286 \\
\hline 230831_at & 23.83 & FRMD5 & 84978 & $\operatorname{chr} 15 \mathrm{q} 15.3$ & Hs. 578544 \\
\hline 1552626_a_at & 21.23 & TMEM163 & 81615 & $\operatorname{chr} 2$ q21.3 & Hs. 369471 \\
\hline 206343_s_at & 17.39 & $N R G 1$ & 3084 & chr8 p12 & Hs. 453951 \\
\hline 213524_s_at & 17.05 & GOS2 & 50486 & $\operatorname{chr} 1 \mathrm{q} 32.2$ & Hs. 432132 \\
\hline 203699_s_at & 15.19 & $\mathrm{DIO} 2$ & 1734 & $\operatorname{chr} 14 \mathrm{q} 31.1$ & Hs. 202354 \\
\hline 212158_at & 14.85 & $S D C 2$ & 6383 & chr8 q22.1 & Hs. 1501 \\
\hline 222925_at & 13.87 & $D C D C 2$ & 51473 & chr6 p22.3 & Hs. 61345 \\
\hline 205786_s_at & 13.09 & ITGAM & 3684 & chr16 p11.2 & Hs. 172631 \\
\hline 241288_at & 12.99 & & & chr6 p21.1 & \\
\hline 209270_at & 11.94 & $L A M B 3$ & 3914 & chr1 q32.2 & Hs. 497636 \\
\hline 229800_at & 11.88 & $D C L K 1$ & 9201 & $\operatorname{chr} 13 \mathrm{q} 13.3$ & Hs. 507755 \\
\hline 211030_s_at & 11.84 & SLC6A6 & 6533 & chr3 p25.1 & Hs. 529488 \\
\hline 201288_at & 11.65 & $A R H G D I B$ & 397 & $\operatorname{chr} 12$ p 12.3 & Hs. 504877 \\
\hline 210118_s_at & 11.30 & $I L 1 A$ & 3552 & $\operatorname{chr} 2$ q14.1 & Hs. 1722 \\
\hline 215303_at & 11.22 & DCLK1 & 9201 & $\operatorname{chr} 13$ q13.3 & Hs. 507755 \\
\hline 231766_s_at & 10.95 & COL12A1 & 1303 & chr6 q14.1 & Hs. 101302 \\
\hline 208230_s_at & 10.41 & $N R G 1$ & 3084 & chr8 p12 & Hs. 453951 \\
\hline
\end{tabular}

S, selected; P, parent; FC, Fold change.

\section{Results}

Establishment of highly invasive cell lines. Highly invasive cell lines with obvious differences between $\mathrm{P}$ and $\mathrm{S}$ were obtained from the parental PANC-1, KP3, BxPC-3, and TCC-PAN2 cells (Fig. 1). In particular, PANC-1 showed a high cell index soon after the fourth round of selection (S) and this showed a tendency to increase thereafter. Although the other three cell lines did not show a clear increase over P immediately after selection, the value showed a clear increase after 10 hours for KP3 and BxPC-3 and after 20 hours for TCC-PAN2. On the other hand, for the AsPC-1 and MIA PaCa-2 lines, there was no tendency for invasion to increase even after the fourth round of selection. The first four cell lines formed the highly invasive group and the other two, the low invasive group.

Search for genes involved in enhanced invasiveness. Expression changes of 38,500 genes were analyzed. These analyzed genes were shown in Volcano plot and heat map (Figs. 2 and 3). Among them, the genes whose expression was clearly enhanced in $\mathrm{S}$ compared to $\mathrm{P}$ in the four highly invasive cell lines, and not enhanced in either $\mathrm{S}$ or $\mathrm{P}$ in the two low invasive cell lines, were roughly extracted. Table II shows the 20 genes selected in descending order of FC value. Furthermore, genes with a high FC value in the highly invasive cells, and which had been thought to be possibly involved in metastasis and invasiveness in previous studies, were selected. Finally, the genes IL-32, PTX3, ARHGDIB, and PCYT1B were selected.
Validation by $R T-P C R$. The relative expression levels of the above genes were measured by RT-PCR. When P and S were compared, although there was a difference depending on the gene, in the highly invasive group, expression tended to be enhanced in $\mathrm{S}$ cells and, in particular, $I L-32$ showed statistically significant enhancement (Fig. 4, left column). On the other hand, in the low invasive group, no significant difference was found between $\mathrm{P}$ and $\mathrm{S}$ for any of the genes (Fig. 4, middle column). Moreover, in the highly invasive group $\mathrm{S}$ and the low invasive group $\mathrm{S}$ cells, comparison of $I L-32$ and PTX3 showed a significant tendency for higher levels of expression in the highly invasive group. On the other hand, in ARHGHDIB and PCYTIB cells, although there is a large difference in expression depending on the cell, each gene expression within $\mathrm{BxPC}-3$ and PANC-1 tended to be low and no significant difference was observed in the expression level between $\mathrm{S}$ of highly invasive group and $\mathrm{P}$ of highly invasive group or $\mathrm{S}$ of low invasive group (Fig. 4, left and right column).

Protein expression. In RT-PCR, IL-32 showed significant gene expression differences between the highly invasive group and the low invasive group, so it was judged that this gene is strongly related to invasiveness. In addition, western blotting was performed to confirm the expression of the gene at the protein level (Fig. 5). IL-32 was highly expressed in the $\mathrm{S}$ lines of the highly invasive group, compared to $\mathrm{P}$. On the other hand, in the low invasive group, expression of IL-32 was hardly observed in either $\mathrm{P}$ or S. 

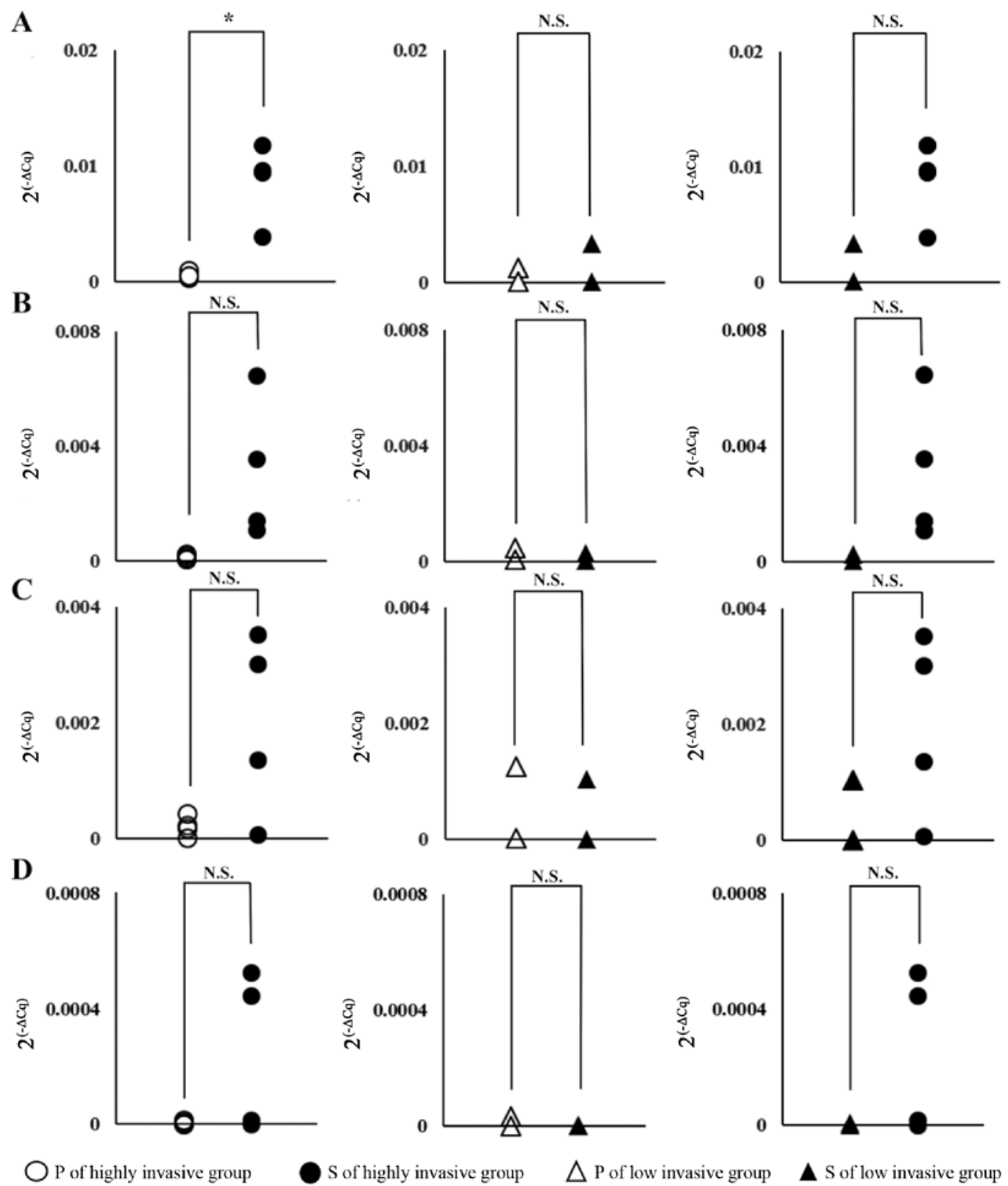

Figure 4. Relative expression of mRNA. Comparing P and S, IL-32 showed a significant difference and PTX3 showed a significant tendency (left lane). In contrast, expression of these genes did not vary significantly in the low-invasive group (center lane). IL-32 and PTX3 exhibit marginally significant expression in $\mathrm{S}$ cells of the highly invasive group compared to $\mathrm{S}$ cells of the low invasive group but other genes did not (right lane). (A) IL-32, (B) PTX3, (C) ARHGDIB, and (D) PCYT1B. "P<0.05. IL, interleukin; N.S, not significant; S, selected; P, parent.

Immunocytochemical study. In order to confirm the expression of IL-32 in pancreatic cancer cells, immunocytochemical studies were performed using BxPC-3, which was one of the highly invasive group (Fig. 6). Structural comparison of $\mathrm{P}$ and $\mathrm{S}$ showed that $\mathrm{P}$ cells had tightly adhered to each other, but the adherences of $\mathrm{S}$ cells were low and showed solitariness. In $\mathrm{S}$ cells, IL-32 expression were observed in the cytoplasm of many cells, whereas in contrast there was almost no expression in $\mathrm{P}$ cells

\section{Discussion}

Pancreatic cancer has an extremely poor prognosis with the highest mortality rate of all neoplasms (10). It is ranked seventh in terms of the number of cancer deaths and it has been estimated that around 330,000 people died of the disease in 2012. Morbidity rates are also on the increase and are expected to rank second by 2030 (11). Pancreatic cancer spreads easily at the early stage of local lesions, often resulting in distant metastases and, even if the cancer is diagnosed clinically, often it is already difficult to achieve complete surgical resection (2). Although various novel findings on the basis of pancreatic cancer have accumulated recently, application to the clinical field has not been achieved completely. Therefore, further studies of the biological properties of pancreatic cancer that may contribute to the development of novel therapeutics are needed.

One biological feature of pancreatic cancer is the dense interstitium, comprising abundant fibrous components and known as the desmoplastic response. It has been suggested 


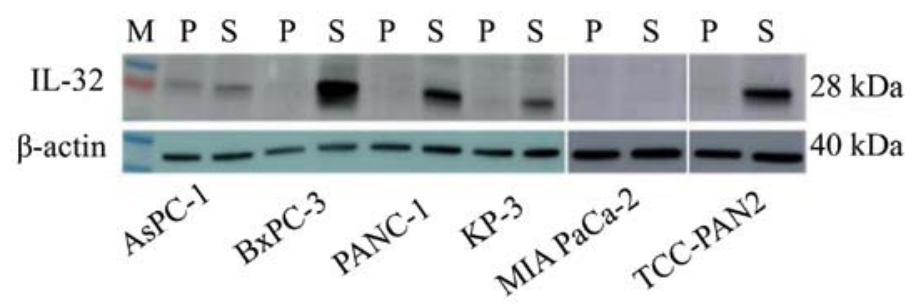

Figure 5. Western blot analysis of IL-32. Significantly high expression was observed in the S cells of the highly invasive group but not in P or the low invasive group. M, marker proteins. IL, interleukin; S, selected; P, parent.
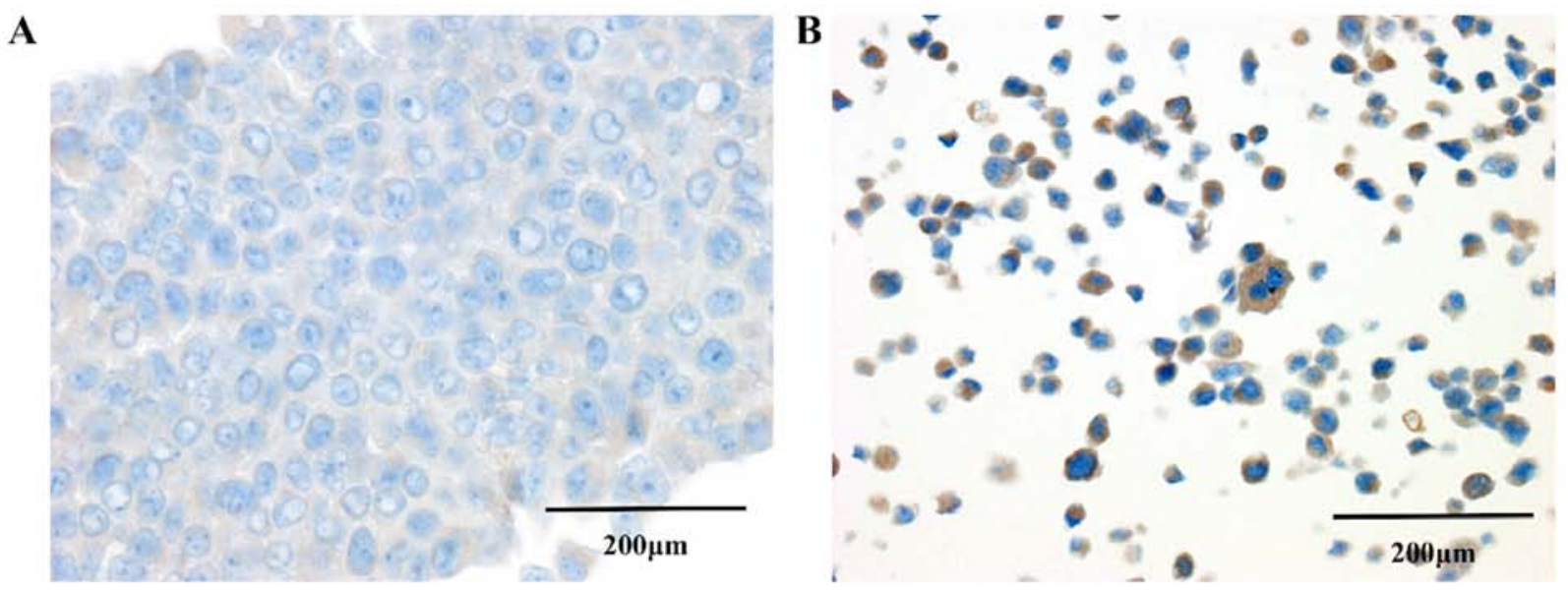

Figure 6. Immunocytochemistry of IL-32 in BxPC-3. (A) P ofBxPC-3 cells. IL-32 expression is hardly observed. (B) S of BxPC-3 cells. IL-32-positive cells may be seen. IL, interleukin; S, selected; P, parent

that this highly fibrotic reaction inhibits the entry of immune cells and anticancer drugs into the tumor tissue. This reaction may contribute to the progression of pathogenesis through certain cell signaling pathways (12). On the other hand, the desmoplasia might be expected to have the opposite effect on tumor progression, especially invasion and metastasis. However, in fact, while pancreatic cancer cells form a hard stroma in tumor tissue, the tumor cells infiltrate this easily. So what are the mechanisms and factors involved in regulating this high invasiveness? Many factors that regulate the cancer cell invasion have been reported for pancreatic cancer, including MMP, TGF- $\beta$ and other molecules $(4,5)$. Unfortunately, these alone cannot explain the high invasiveness of pancreatic cancer. Therefore, we conducted research using a new method to identify factors that control the high invasiveness of pancreatic cancer cells.

In most studies of the molecules involved in invasiveness, the predicted factors have been selected first and examined to determine their influence on invasiveness. However, this approach requires a substantial amount of time and effort to identify the factors involved in invasion. In order to identify candidate molecules from a large number of factors that may be involved, it may be considered best and effective to find these target molecules by comprehensively analyzing gene expression in cells with varying degrees of invasiveness. In this study, we used the IA method to establish four highly invasive cell lines from six pancreatic cancer cell lines. Although, in each case, the original $\mathrm{P}$ cell line is an established cell line, it may be in a state in which cell populations with various characteristics are mixed. By selecting highly invasive cell from the total population, it may be possible to investigate changes occurring in these cells. On the other hand, the lines AsPC-1 and MIA PaCa-2 did not provide cells with enhanced invasiveness. One of them, MIA $\mathrm{PaCa}-2$, has been reported to have low metastatic potential in a liver metastasis assay in nude mice (13) and it may be that this cell line is inherently inferior in its ability to metastasize or invade.

From a comprehensive genetic analysis, the expression levels of four genes, $I L-32, P T X 3, A R H G D I B$ and PCYT1B, were found to be enhanced in all $\mathrm{S}$ cells showing high invasiveness, greater than the original $\mathrm{P}$ cells with low invasive potential. Validation with real time PCR also confirmed that these genes had tended to increased expression in highly invasive cells. Above all, the upregulation of $I L-32$ gene expression was remarkable, 42 times in terms of fold-change. In addition, IL-32 was markedly increased in highly invasive cells at the level of protein expression. Furthermore, in our another experiment, immunohistochemical examination of IL-32 in pancreatic cancer tissue showed high expression in tumor cells and many tumor cells at the invasive front showed a tendency for high IL-32 expression, but only a small number of cells expressed IL-32 in normal tissues (data not shown). These findings suggest that the invasive properties of tumor cell are strongly correlated with IL-32 expression.

IL-32 is a relatively recently discovered member of the IL family and was reported in 2005 as an inflammatory cytokine involved in the induction of TNF- $\alpha$ and IL-8 (14). So far, nine isoforms $(\alpha, \beta, \gamma, \delta, \varepsilon, \zeta, \eta, \theta$, small) have been reported as 
splice variants. Recently, several papers have reported the association between IL-32 and tumors, such as involvement in the development and invasiveness of hepatocellular carcinoma (15) and breast cancer (16). On the other hand, it has also been reported that cases of renal cell carcinoma with high IL-32 expression have a better prognosis (17). These apparently contradictory results may stem from differences not only in the biological properties of individual isoforms but also in the mechanisms of expression or action, which may vary among different tumor tissues (18). Regarding the involvement of IL-32 in pancreatic diseases, it has reported that expression of IL-32 was enhanced in chronic pancreatitis and, especially, in pancreatic cancer cells (19). On the other hand, it has also been reported that overexpression of IL-32 $\alpha$ suppresses EMT in pancreatic cancer (20). As a general view of the association between IL-32 and EMT, IL-32 $\gamma$ promoted EMT via Akt and NFxB signaling, and IL-32 $\beta$ is via STAT3, whereas IL-32 $\alpha$ and IL-32 $\theta$ are thought to suppress STAT3 signaling and then block EMT. Thus, each isoform of IL-32 seems to exhibit various functions in an organ-specific manner.

In conclusion, IL-32 is known to be involved in many neoplastic lesions and also in disease progression in pancreatic cancer. In our study, among those cells showing increased expression in common with a high invasiveness in the invasion assay, it was revealed that IL-32 expression has a positive correlation with invasiveness. In the future, it will be necessary to confirm that IL-32 expression truly controls the invasiveness of pancreatic cancer. For example, it is necessary to determine whether the invasion ability can be reduced by knockdown using siRNA against $I L-32$ and whether or not low invasive cells in which IL-32 is forcibly expressed have enhanced invasiveness. Evaluating the expression of IL-32 comparing high metastatic pancreatic cancer and normal tissue is also one of the things we should do. We would like to accumulate many cases and examine the behavior of IL-32 at each stage of pancreatic cancer. In addition, it is necessary to investigate in detail what position IL-32 plays in the signaling pathways for invasion and what role it plays. We are currently studying this and hypothesized that although details are under study, IL-32 improves invasion ability of pancreatic cancer cell through upregulating EMT. We also assume that NFKB and STAT3 signal pathway may also involve in increased invasiveness. We will make these hypotheses more systematic in the future report.

\section{Acknowledgements}

The authors would like to thank Miss Sayoko Sumiyoshi and Miss Miho Metoki (Department of Diagnostic Pathology, Faculty of Medicine, Academic Assembly, University of Toyama), who are medical students, for providing useful advice through their research on IL-32.

\section{Funding}

This study was supported by Japan Society for the Promotion of Science (JSPS) Grants-in-Aid for Scientific Research (KAKENHI; grant no. 16K08707).

\section{Availability of data and materials}

The datasets used and/or analyzed during the present study are available from the corresponding author on reasonable request.

\section{Authors' contributions}

KT and JI designed the study, and KT mainly performed the experiments and wrote the initial draft of the manuscript. JI also contributed to interpretation of data, and assisted in the preparation of the manuscript. AS, $\mathrm{HH}$ and TNi engaged in the collection of some experimental data and they also gave technical and intellectual advice on the acquired data, especially in the interpretation of microarray assays and RT-PCR. AN, ST, TM and TNa advised on the construction of the study design and especially on the interpretation of data on invasion assessment and critically reviewed the manuscript. All authors have read and admitted the final manuscript.

\section{Ethics approval and consent to participate}

Not applicable.

\section{Patient consent for publication}

Not applicable.

\section{Competing interests}

The authors declare that they have no competing interests.

\section{References}

1. Vincent A, Herman J, Schulick R, Hruban RH and Goggins M: Pancreatic cancer. Lancet 378: 607-620, 2011.

2. Kleeff J, Korc M, Apte M, La Vecchia C, Johnson CD, Biankin AV, Neale RE, Tempero M, Tuveson DA, Hruban RH, et al: Pancreatic cancer. Nat Rev Dis Primers 2: 16022, 2016.

3. Pelosi E, Castelli G and Testa U: Pancreatic Cancer: Molecular characterization, clonal evolution and cancer stem cells. Biomedicines 5: 5, 2017

4. Luo J, Chen XQ and Li P: The role of TGF- $\beta$ and its receptors in gastrointestinal cancers. Transl Oncol 12: 475-484, 2019.

5. Miyazono K, Katsuno Y, Koinuma D, Ehata S and Morikawa M: Intracellular and extracellular TGF- $\beta$ signaling in cancer: Some recent topics. Front Med 12: 387-411, 2018.

6. Kawamata H, Furihata T, Omotehara F, Sakai T, Horiuchi H, Shinagawa Y, Imura J, Ohkura Y, Tachibana M, Kubota K, et al: Identification of genes differentially expressed in a newly isolated human metastasizing esophageal cancer cell line, T.Tn-AT1, by cDNA microarray. Cancer Sci 94: 699-706, 2003.

7. Jones S, Zhang X, Parsons DW, Lin JC, Leary RJ, Angenendt P, Mankoo P, Carter H, Kamiyama H, Jimeno A, et al: Core signaling pathways in human pancreatic cancers revealed by global genomic analyses. Science 321: 1801-1806, 2008.

8. Iacobuzio-Donahue CA, Velculescu VE, Wolfgang CL and Hruban RH: Genetic basis of pancreas cancer development and progression: Insights from whole-exome and whole-genome sequencing. Clin Cancer Res 18: 4257-4265, 2012.

9. Livak KJ and Schmittgen TD: Analysis of relative gene expression data using real-time quantitative PCR and the 2(-Delta Delta C(T)) Method. Methods 25: 402-408, 2001.

10. Ilic $\mathrm{M}$ and Ilic I: Epidemiology of pancreatic cancer. World J Gastroenterol 22: 9694-9705, 2016.

11. Rahib L, Smith BD, Aizenberg R, Rosenzweig AB, Fleshman JM and Matrisian LM: Projecting cancer incidence and deaths to 2030: The unexpected burden of thyroid, liver, and pancreas cancers in the United States. Cancer Res 74: 2913-2921, 2014 
12. Laklai H, Miroshnikova YA, Pickup MW, Collisson EA, Kim GE, Barrett AS, Hill RC, Lakins JN, Schlaepfer DD, Mouw JK, et al: Genotype tunes pancreatic ductal adenocarcinoma tissue tension to induce matricellular fibrosis and tumor progression. Nat Med 22: 497-505, 2016.

13. Sugimoto Y, Morita R, Hikiji K, Imura G, Ogata Y, Yasuda D, Kono $\mathrm{A}$ and Iguchi $\mathrm{H}$ : Alteration of the CDKN2A gene in pancreatic cancers: Is it a late event in the progression of pancreatic cancer? Int J Oncol 13: 669-676, 1998.

14. Kim SH, Han SY, Azam T, Yoon DY and Dinarello CA Interleukin-32: A cytokine and inducer of TNFalpha. Immunity 22: 131-142, 2005.

15. Kang YH, Park MY, Yoon DY, Han SR, Lee CI, Ji NY, Myung PK, Lee HG, Kim JW, Yeom YI, et al: Dysregulation of overexpressed IL-32 $\alpha$ in hepatocellular carcinoma suppresses cell growth and induces apoptosis through inactivation of NF- $x \mathrm{~B}$ and Bcl-2. Cancer Lett 318: 226-233, 2012.

16. Wang S, Chen F and Tang L: IL-32 promotes breast cancer cell growth and invasiveness. Oncol Lett 9: 305-307, 2015.
17. Lee HJ, Liang ZL, Huang SM, Lim JS, Yoon DY, Lee HJ and Kim JM: Overexpression of IL-32 is a novel prognostic factor in patients with localized clear cell renal cell carcinoma. Oncol Lett 3: 490-496, 2012.

18. Sloot YJE, Smit JW, Joosten LAB and Netea-Maier RT: Insights into the role of IL-32 in cancer. Semin Immunol 38: 24-32, 2018.

19. Nishida A, Andoh A, Inatomi O and Fujiyama Y: Interleukin-32 expression in the pancreas. J Biol Chem 284: 17868-17876, 2009.

20. Chen J, Wang S, Su J, Chu G, You H, Chen Z, Sun H, Chen B and Zhou M: Interleukin-32 $\alpha$ inactivates JAK2/STAT3 signaling and reverses interleukin-6-induced epithelial-mesenchymal transition, invasion, and metastasis in pancreatic cancer cells. OncoTargets Ther 9: 4225-4237, 2016.

This work is licensed under a Creative Commons

Attribution-NonCommercial-NoDerivatives

4.0 International (CC BY-NC-ND 4.0) License. 